\title{
Pacific Hagfish, Eptatretus stoutii, Spotted Ratfish, Hydrolagus colliei, and Scavenger Activity on Tethered Carrion in Subtidal Benthic Communities off Western Vancouver Island
}

\author{
SARAh Davies $^{1}$, Ali Griffiths ${ }^{1}$, and T. E. ReImCHEN ${ }^{2}$ \\ ${ }^{1}$ Bamfield Marine Sciences Centre, Bamfield, British Columbia V0R 1B0 Canada \\ ${ }^{2}$ Department of Biology, P.O. Box 3020, University of Victoria, Victoria, British Columbia V8W 3N5 Canada; e-mail: reimchen@ \\ uvic.ca (corresponding author)
}

Davies, Sarah, Ali Griffiths, and T. E. Reimchen. 2006. Pacific Hagfish, Eptatretus stoutii, Spotted Ratfish, Hydrolagus colliei, and scavenger activity on tethered carrion in subtidal benthic communities off Western Vancouver Island. Canadian Field-Naturalist 120(3): 363-366.

The influence of pelagic carrion food falls on marine benthic scavenging communities was investigated at two depths (10 m, $50 \mathrm{~m}$ ) in Barkley Sound, west Vancouver Island, British Columbia from 12 May to 4 June, 2003. A remotely operated vehicle (ROV) equipped with video cameras was used to monitor anchored carrion (15 kg pig leg) during daylight and darkness. The videos were subsequently analyzed for species diversity, abundance and the intensity of scavenging. At $10 \mathrm{~m}$, Redrock Crab (Cancer productus) and Kelp Greenling (Hexagrammos decagrammus) dominated, while at $50 \mathrm{~m}$, Spot Shrimp (Pandalus platyceros), Spotted Ratfish (Hydrolagus colliei) and Pacific Hagfish (Eptatretus stoutii) were the dominant species, most of which were nocturnal. Hagfish were the major consumers of the carrion and after 23 days, no soft tissues remained at $50 \mathrm{~m}$ while $40 \%$ remained at $10 \mathrm{~m}$. Within 24 hours of the carrion deployment, two of eleven ratfish succumbed, probably due to the direct clogging effects of hagfish mucus on the respiratory apparatus of the ratfish. These field observations are consistent with laboratory results suggesting high efficacy of hagfish mucus in competitive interactions.

Key Words: Pacific Hagfish, Eptatretus stoutii, Spotted Ratfish, Hydrolagus colliei, Spot Shrimp, Pandalus platyceros, Redrock Crab, Cancer productus, Kelp Greenling, Hexagrammos decagrammus, marine scavengers, carrion, remotely operated vehicle (ROV), nutrient cycling, Vancouver Island, British Columbia.

Vertebrate carcasses provide an episodic but highly important food source for benthic organisms, particularly at depths beyond the zones of primary productivity (Lalli and Parsons 2001). Such carcasses have recently become of interest due to increasing discards in fisheries as this may shift benthic community structure (Collins et al. 1999). Species such as ratfish and benthic sharks as well as crustaceans may benefit from such food falls (Collins et al. 1999; Tamburri and Barry 1999). There are few descriptions of the scavenging community or the interactions among species around these carcasses.

We anchored carrion at two depths $(10 \mathrm{~m}, 50 \mathrm{~m})$ in Barkley Sound, west Vancouver Island, British Columbia and monitored the carrion with a remotely-operated vehicle (ROV). We provide here an examination of scavenger diversity, abundance and interactions among species during daylight and darkness.

\section{Methods}

Two soft-substrate sites $\left(10 \mathrm{~m}, 50 \mathrm{~m}: 48^{\circ} 50^{\prime} \mathrm{N}\right.$, $125^{\circ} 10^{\prime} \mathrm{W}$ ) in Mackenzie Anchorage, Barkley Sound, British Columbia were chosen and single $15 \mathrm{~kg}$ pig legs (frozen with intact skin) were anchored at each site. Initial deployment occurred at $1030 \mathrm{~h}$ on 12 May 2003. An ROV (Deep Ocean Engineering Phantom $\mathrm{HD} 2+)$ equipped with $5 \mathrm{~mW} 635 \mathrm{~nm}$ lasers $(10 \mathrm{~cm}$ standard for scaling) and 250W Tungsten-Halogen lights were used to monitor the carrion. The ROV was stationed beside the carrion for 30 minutes during night trials and 15 minutes (due to less activity) during day trials. We switched the ROV lights off for 1-2 minutes on several occasions during the night monitoring phase but observed no changes in activity. Before surfacing with the ROV, areas within $5 \mathrm{~m}$ of carrion were scanned for individuals. Day trials of the ROV were carried out near $1400 \mathrm{~h}$ and replicated on three occasions $(13,14$, 16 May) while night trials occurred near $2230 \mathrm{~h}$ and were replicated on four occasions (12, 13, 14, 23 May). The experiment was terminated on 4 June and the two carcasses returned to the surface and relative tissues were estimated. Twelve hours of videotape were analyzed. Percent of remaining carrion and sizes of scavengers were estimated from the laser standards. Species were identified and all individuals within several metres of the carrion were counted. General behavior of the species was noted. Paired sampled t-tests were used to test for significant differences for species and abundance between sites and within sites.

\section{Results}

Species Abundance

Carrion anchored at the two depths attracted a different assemblage of species (Figure 1). At $10 \mathrm{~m}$, Redrock Crab (Cancer productus) $(7-20 \mathrm{~cm})$, and Kelp Greenling (Hexagrammos decagrammus) $(11-23 \mathrm{~cm})$ 

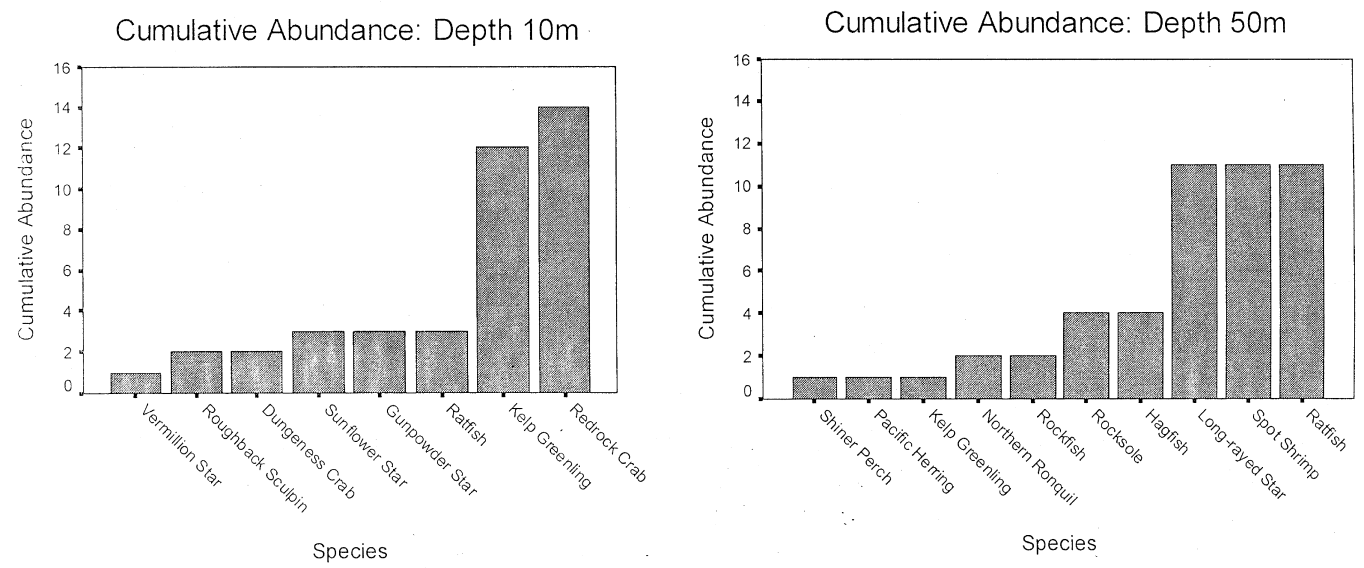

FIGURE 1. Cumulative species abundances of scavengers observed at carrion anchored at $10 \mathrm{~m}$ and $50 \mathrm{~m}$ in Barkley Sound, Vancouver Island.

were the dominant species, while at $50 \mathrm{~m}$, Long-rayed Star (Stylasterias forriei) $(20-60 \mathrm{~cm})$, Spot Shrimp (Pandalus platyceros) $(12-20 \mathrm{~cm})$, Spotted Ratfish (Hydrolagus colliei) (18-25 cm), Pacific Hagfish (35$65 \mathrm{~cm}$ ) and Rocksole (Lepidosetta bilineata) were dominant. Only two of 16 species (Spotted Ratfish, Kelp Greenling) were common to both sites (Figure 2). Although all species were in direct contact or immediately adjacent to the carrion, only six species actively foraged off the carrion (Pacific Hagfish, Redrock Crab, Dungeness Crab (Cancer magister), Sunflower Star (Pycnopodia helianthoides), Long-rayed Star (Orthasterias koehleri), and Spot Shrimp). Hagfish undertook extensive burrowing and excavations and were the major consumers of tissues. Ratfish swam commonly in close vicinity to the carrion but we observed no foraging activity. Daily consumption rates at $10 \mathrm{~m}$ were initially high and then decreased while at the $50 \mathrm{~m}$ site, the rate increased throughout the duration of sampling. On the last ROV survey (Day 23), $40 \%$ of the soft tissues remained at the 10 $\mathrm{m}$ site while only bone remained at the $50 \mathrm{~m}$ site.

\section{Diel variations}

The scavenger community differed during daylight and darkness (Figure 3). At both sites there were increased numbers of species observed during darkness (10 m Day, 5 , Night, 11; 50 m Day, 5, Night, 9). At $10 \mathrm{~m}$ depth, nocturnal scavengers were Redrock Crab, Spotted Ratfish, Roughback Sculpin (Chitonotus pugetensis), and Dungeness Crab. At $50 \mathrm{~m}$, Long rayed Star was present in both day and night trials and was seen continually in all surveys. Northern Ronquil (Ronquilus jordani), Rocksole and Kelp Greenling were seen only during day trials. Pacific Hagfish, Spotted Ratfish, and Spot Shrimp were dominant at night.

\section{Behavioural interactions within and among scavenger species}

Diverse interactions occurred among species. Redrock Crabs defended the carrion by direct attacks against conspecifics as well as against Kelp Greenling. Pacific Hagfish excavated burrows within the carrion by rasping, full-body spinning and occasional knotting. Spotted Ratfish swam in close vicinity to the carrion and in several instances directly contacted the hagfish but we saw no evidence of agonistic behaviour. However, during the second ROV flight, we observed two freshly deceased ratfish lying within several meters of the carrion. There was no evidence of external damage to either ratfish but there was extensive subsurface haemorrhaging around the mouth on one ratfish and strands of mucus on the second and we infer rapid respiratory failure from the hagfish mucus that was prevalent in the water column around the carrion. During the ROV survey, hagfish did not feed on dead ratfish. Strands of mucus that separated from hagfish when feeding on the carrion were very adhesive as the strands disabled thruster motors of the ROV.

\section{Discussion}

High productivity and the recycling of nutrients sustain large populations of benthic organisms in the waters of the continental shelf (Nybakken 2001). We examined an experimental food fall at two $(10 \mathrm{~m}, 50 \mathrm{~m})$ natural habitats in coastal British Columbia and found that species assemblages differed between depths and with diel variation. The intensity of scavenging was greater at increased depth and increased during night, which corroborates well with other observations on scavenging communities (Collins et al. 1999). Shifts in diel patterns to nocturnal activity are common in marine 


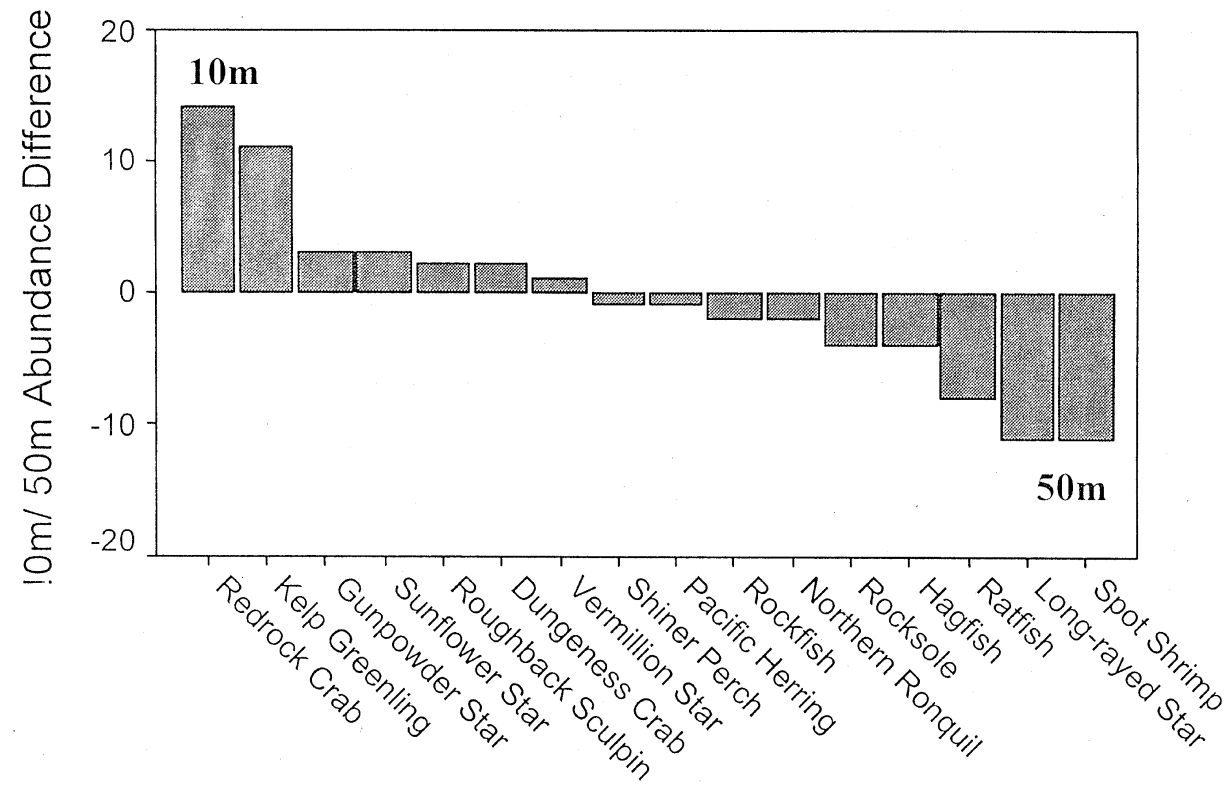

FIGURE 2. Relational abundance of scavenger species at carrion anchored at $10 \mathrm{~m}$ and $50 \mathrm{~m}$ depth (number of individuals at $10 \mathrm{~m}$ - number of individuals at $50 \mathrm{~m}$ depth), Barkley Sound. Positive values show greater occurrence at $10 \mathrm{~m}$ depth. Negative values show greater occurrence at $50 \mathrm{~m}$ depth.

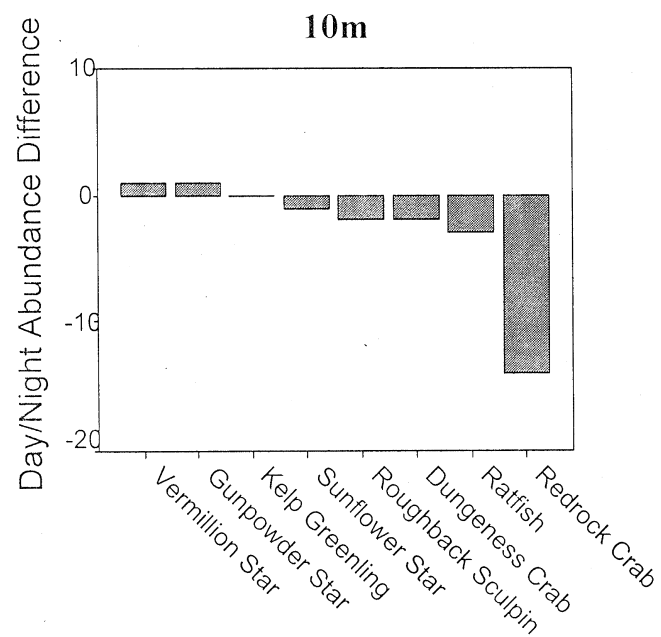

Species

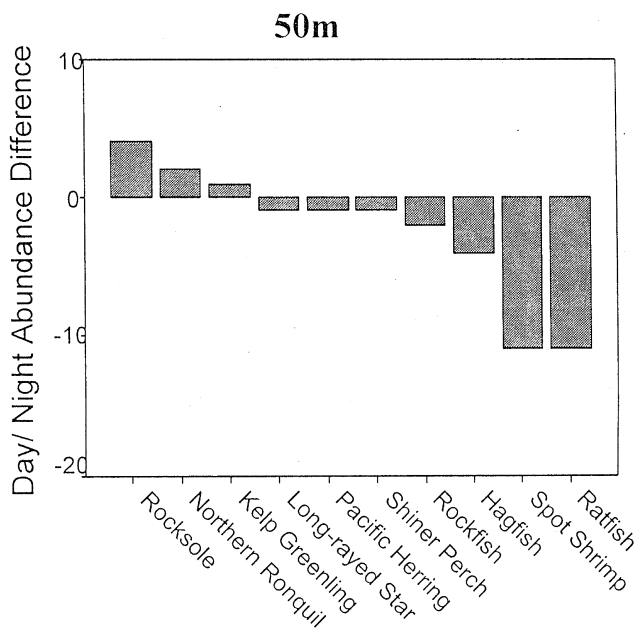

Species

FIGURE 3. Relational abundance of scavenger species due to diel variation (number of individuals during daylight - number of individuals during night). Positive values show greater occurrence during daylight. Negative values show greater occurrence during night.

benthic habitats (Lalli and Parsons 2001) and may reflect predator avoidance or reduction in competition. The agonistic encounters observed among crabs and fish indicate that carrion represents significant local energy enrichment to the benthic community (Stockton and DeLaca 1982).
Spotted Hagfish were the major scavengers at $50 \mathrm{~m}$ and were largely nocturnal, consistent with the findings of Fernholm (1974). These fish play an important role in the turnover and cycling of nutrients (Lesser et al. 1996; Collins et al. 1999). We observed a much higher rate of tissue loss at the $50 \mathrm{~m}$ site where hagfish 
were prevalent. Since hagfish are dependent on food falls, specialized adaptations to minimize competition are present. Knotting is considered to be an important feeding behavior in which the hagfish attaches to prey with tooth plates and passes a knot from the caudal region anterior towards the head allowing tissues to be ripped off (Collins et al. 1999). We also observed this behavior, but only on a single occasion. Rather, hagfish primarily used full body spinning to pull pieces of tissue from the carrion. Such full body rotation is also present in sharks feeding on large prey and may allow an increase in their effective gape (Helfman et al. 1997).

Hagfish produce copious amounts of slime when feeding, agitated or threatened (Strahan 1963; Tamburri and Barry 1999). There are probably diverse functions to this slime including burrowing, defense and competitive exclusion (Collins et al. 1999). Hagfish burrowed into the carcass up to $3 / 4$ of their total body length. While the mucus may facilitate entry into the carrion, the burrowing would also cover the gills and this would limit gas exchange of the hagfish. This suggests the potential for posterior cutaneous respiration. Lesser et al. (1996) noted that hagfish skin was well-vascularized and hagfish are therefore able to survive with plugged nostrils and no respiratory current across the gills. Slime produced by hagfish has high strength (Fudge et al. 2003) and can also obstruct mouthparts and gills of other species attempting to feed at food falls (Tamburri and Barry 1999; Collins et al. 1999). Our ROV observations are consistent with these suggestions. Two of the ratfish swimming in close proximity to the foraging hagfish quickly succumbed, presumably from loss of respiratory ability. The close proximity suggests high efficacy and rapid effects of the hagfish mucus in natural conditions even under high dilution effects. If these observations are representative, it suggests that hagfish may not only have a substantial competitive advantage over other fish species in these episodic carrion fallouts but also operate as predators through the lethal influences of mucus on other scavengers.

\section{Acknowledgments}

We thank Nimrod Levy for discussion, James Mortimer, John Richards and Janice Pierce for ROV and vessel support, J. Yakimishyn and J. P. Danko for lab and technical support, and the Bamfield Marine Sciences Center for funding this project. TER acknowledges support (A2354) from the Natural Sciences and Research Council of Canada.

\section{Literature Cited}

Collins, M. A., C. Yau, C. P. Nolan, P. M. Bagley, and I. G. Priede. 1999. Behavioral observations on the scavenging fauna of the Patagonian Slope. Journal of the Marine Biological Association of the United Kingdom 79: 963-970.

Fernholm, B. 1974. Diurnal variation in the behavior of the hagfish Eptatretus burgeri. Marine Biology 27: 351-356.

Fudge, D. S., K. H. Gardner, V. T. Forsyth, C. Riekel, and J. M. Gosline. 2003. The mechanical properties of hydrated intermediate filaments: Insights from hagfish slime threads. Biophysical Journal 85: 2015-2027.

Helfman, G. S., B. B. Collette, and D. E. Facey. 1997. The diversity of fishes. Blackwell Science, London.

Lalli, C. M., and T. R. Parsons. 2001. Biological Oceanography: An Introduction. $2^{\text {nd }}$ Edition. Butterworth/Heinemann, Great Britain.

Lesser, M. P., F. H. Mar'tini, and J. B. Heiser. 1996. Ecology of the hagfish, Myxine glutinosa in the Gulf of Maine. I. Metabolic rates and energetics. Journal of Experimental Marine Biology and Ecology 37: 215-225.

Nybakken, J. W. 2001. Marine biology: An ecological approach. $5^{\text {th }}$ edition. Benjamin Cummings, Montreal.

Stockton, W. L., and T. E. DeLaca. 1982. Food falls in the deep sea: occurrence, quality and significance. Deep-Sea Research 29: 157-169.

Strahan, R. 1963. The behaviour of Myxine and other Myxinoids. Pages 22-33 in Biology of Myxine. Edited by A. Broda and R. Fange. Universitetsforlaget, Oslo, Norway.

Tamburri, M. N., and J. P. Barry. 1999. Adaptations for scavenging by three diverse bathyal species, Eptatretus stoutii, Neptunea amianta and Orchomene obtusus. Deep Sea Research I 46: 2079-2093.

Received 26 October 2005

Accepted 16 February 2007 